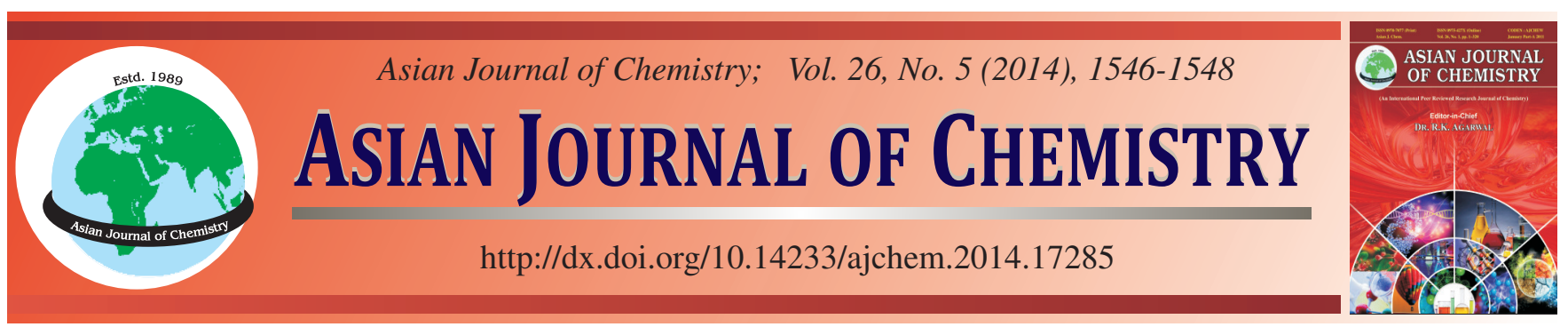

\title{
Characterization of Si-Ti-C-O Matrix Using Polycarbosilane for Fiber Reinforced Ceramic Matrix Composites by Blending Technique $\dagger$
}

\author{
Oк Hyoung Lee, Tae-Eon Kim, Mi Suk Kang and Kwang YeOn Cho*
}

Nano Convergence Intelligence Materials Team, Korea institute of Ceramic Engineering and Technology, Seoul 153-801, Republic of Korea *Corresponding author: Fax: +82 2 32827769; Tel: +82 2 23827711; E-mail: kycho@kicet.re.kr

To fabricate Si-Ti-C-O matrix, we introduced titanium to polycarbosilane by simply mixing titanium isopropoxide and polycarbosilane. The mixed solution was cured at $200^{\circ} \mathrm{C}$ and heat treated at $1300^{\circ} \mathrm{C}$ both with inert atmosphere. We successfully synthesized the Si-Ti-C-O matrix. It is confirmed that Si-Ti-C-O matrix has Si-O-Ti connection by FT-IR spectroscope and TiC phase by XRD analysis. For TiC phase, it is expected that $\mathrm{Si}-\mathrm{Ti}-\mathrm{C}-\mathrm{O}$ matrix composite has better thermal properties like oxygen resistance and mechanical strength at high temperature.

Keywords: Silicon carbide, Titanium carbide, Polycarbosilane, Ceramic matrix composites, Polymer infiltration pyrolysis.

\section{INTRODUCTION}

Silicon carbide ( $\mathrm{SiC}$ ) matrix composites are one of the best promising structural materials for their characteristics such as high mechanical strength and oxidation resistance at high temperature ${ }^{1-3}$. Silicon carbide matrix composites can be fabricated by several method including chemical vapor infiltration $(\mathrm{CVI})^{4}$, precursor infiltration pyrolysis (PIP) ${ }^{5}$, etc. Among these methods, PIP method is the best way for the advantages such as low processing temperature and controllable ceramic compositions. As the PIP precursor, polycarbosilane (PCS) is widely used for $\mathrm{SiC}$ polymer precursor of the high ceramic yield. But during PIP process, PCS should be cured by heating in air at intermediate temperature $\left(100-300{ }^{\circ} \mathrm{C}\right)$. At curing process, oxygen atom makes the cross-linking between $\mathrm{PCS}^{6}$. Polycarbosilane would be more decomposed during high temperature heat treatment without oxygen cross-linking so the low ceramic yield and gas evolution at convert to $\mathrm{SiC}$ matrix. So many groups researched the oxygen-free curing process by using electron beam ${ }^{7}$ or adding hardener ${ }^{8}$. To enhance the mechanical and thermal properties in $\mathrm{SiC}$ matrix, several group tried to the introducing other carbide ceramics $(\mathrm{ZrC}, \mathrm{HfC}, \mathrm{TaC}$, etc $)^{9}$. Titanium carbide ( $\left.\mathrm{TiC}\right)$ is also best candidating ceramic matrix for ultra-high thermal stability, high ablation resistance, low thermal conductivity because of make the high young's modulus and locally low elongations ${ }^{10,11}$. It is widely reported that the carbon fiber reinforced $\mathrm{SiC}-\mathrm{TiC}$ or only $\mathrm{TiC}$ matrix composites prepared to various technique such as $\mathrm{TiC}$ doping, mixed $\mathrm{TiC}$ containing precursor into $\mathrm{SiC}$ matrix.

In this study, we tried to make the solution for PIP process by using PCS/titanium isopropoxide than only polytitanocarbosilane (PTCS). It is presumed that titanium isopropoxide could make cross-linking with PCS. It introduces that the titanium was formed by $\mathrm{Si}-\mathrm{O}-\mathrm{Ti}$ than thermal curing process by oxygen cross-liking in $\mathrm{Si}-\mathrm{O}-\mathrm{Si}$ formation. Also, after high temperature pyrolysis, TiC phase is expected. For the properties of $\mathrm{TiC}$, thermal stability of the fabricated matrix could be increased. To fabricate Si-Ti-C-O matrix, we used PCS, titanium isopropoxide and divinylbenzene. The solution was cured in inert atmosphere and heat treated at $1300{ }^{\circ} \mathrm{C}$. The fabricated matrix was analyzed by X-ray diffraction, thermal stability analysis, infrared spectroscopy and scanning electron microscope.

\section{EXPERIMENTAL}

Preparation of Si-Ti-C-O marix: Before making the solution, properties of PCS were analyzed by GPC and softening point and melting point. Table-1 shows the properties of PCS including molecular weight and softening point and melting point. Solution for Si-Ti-C-O matrix was prepared by mixing PCS (ToBeM Tech, Korea), titanium isopropoxide (TIP, Sigma,

†Presented at The 7th International Conference on Multi-functional Materials and Applications, held on 22-24 November 2013, Anhui University of Science \& Technology, Huainan, Anhui Province, P.R. China 


\begin{tabular}{cccccc}
\hline \multicolumn{6}{c}{ TABLE-1 } \\
\multicolumn{6}{c}{ PROPERTIES OF POLYCARBOSILANE BY GPC DATA } \\
\multicolumn{3}{c}{ AND SOFTENING AND MELTING POINTS ANALYSIS } \\
\hline Material $\begin{array}{c}\mathrm{Mn} \\
\text { (Daltons) }\end{array}$ & $\begin{array}{c}\text { Mw } \\
\text { (Daltons) }\end{array}$ & $\begin{array}{c}\text { Softening } \\
\text { point } \\
\left({ }^{\circ} \mathrm{C}\right)\end{array}$ & $\begin{array}{c}\text { Melting } \\
\text { point } \\
\left({ }^{\circ} \mathrm{C}\right)\end{array}$ & Company \\
\hline PCS & 1458 & 3611 & 221 & 255 & $\begin{array}{c}\text { ToBeM } \\
\text { Tech. }\end{array}$ \\
\hline
\end{tabular}

Aldrich) and divinylbenzene (DVB, Sigma-Aldrich) for the cross-linking agent. Polycarbosilane and ZP were mixed with composition of $45 \%$ PCS and $55 \%$ TIP. Accordingly, DVB was added at 10 and $20 \%$ rate of PCS weight. Then, the solution was stirred for $12 \mathrm{~h}$ at ambient temperature. Curing of mixed solution was performed at $180^{\circ} \mathrm{C}$ for $4 \mathrm{~h}$ with inert atmosphere. As-cured compounds (PCS/TIP/DVB) were pyrolyzed at $1300{ }^{\circ} \mathrm{C}$ for $3 \mathrm{~h}$ at a rate of $10^{\circ} \mathrm{C} / \mathrm{min}$ under argon atmosphere in graphite furnace. Fig. 1 present the experimental procedure for the preparation of Si-Ti-C-O matrix. Cured and pyrolyzed samples of characterization and properties was investigated, respectively.

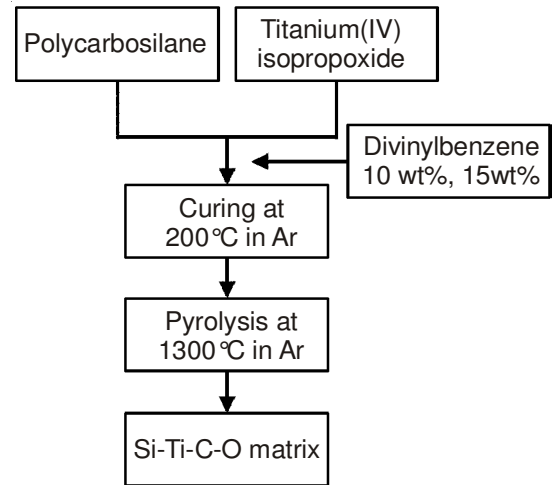

Fig. 1. Experimental procedure for the preparation of Si-Ti-O-C matrix

Characterization and properties analysis of Si-Ti-CO matrix: For confirming the functional group, thermal behaviour, crystallinity and elemental composition in morphologies were analyzed by Fourier transform infrared spectroscopy (FTIR, Jasco-4100, Japan) by attenuated total reflectance (ATR) mode in wavelength of $4000-650 \mathrm{~cm}^{-1}$, thermogravimetric analysis (TGA, Mettler toledo-851e, Switzerland), X-ray diffraction (XRD, Rigaku Miniflex, Japan), field emission-scanning electron microscope (FE-SEM, Jeol-6100F, Japan) and energy dispersive X-ray spectroscopy (EDS, Genesis 2000 XMS, USA).

\section{RESULTS AND DISCUSSION}

Characterization of the Si-Ti-C-O matrix: Fig. 2(a), (b) presents the XRD pattern of Si-Ti-C-O matrix according to DVB weight. Generally, XRD patterns of amorphous $\mathrm{SiC}$ showed three peaks at $35.8,60.4$ and $72.1^{\circ}$ corresponding to reflections from the (111), (222) and (311) planes of $\beta$-SiC, respectively. In the case of $\mathrm{TiC}$, two peaks increase at $41.6^{\circ}$ and $76.2^{\circ}$ corresponding to reflections from (200) and (222) planes, respectively. $\beta$-SiC phase was included TiC cubic phase at the (111), (222) and (311) planes. And, crystallinity of $\beta$ $\mathrm{SiC}$ and $\mathrm{TiC}$ was not seen according to the different DVB weight.

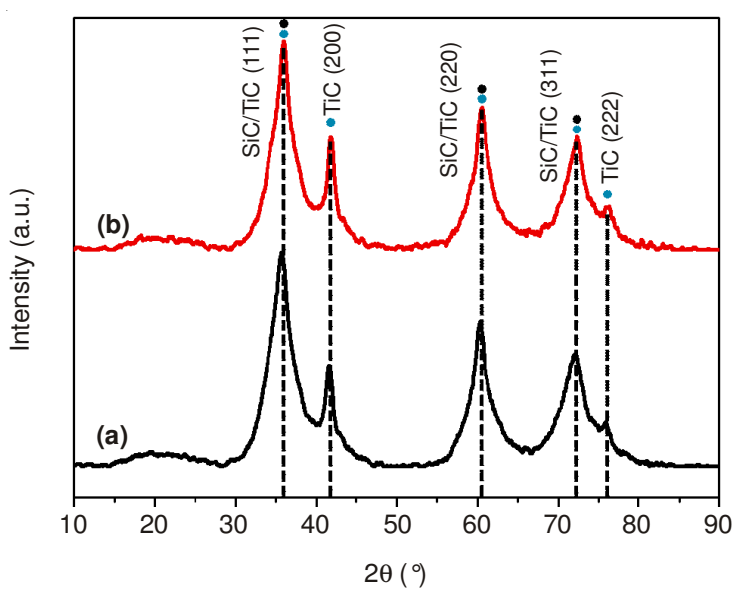

Fig. 2. XRD patterns of pyrolyzed (a) DVB $10 \mathrm{wt} \%$ in PCS/TIP and (b) DVB 15 wt \% in PCS/TIP at $1300{ }^{\circ} \mathrm{C}$ in argon atmosphere

FT-IR spectra displays the functional group of PCS and cured PCS/TIP and DVB (10, 15 wt \%) in Fig. 3(a-c). In case of the PCS, the peak observed at 1408 and $1355 \mathrm{~cm}^{-1}$ can be assigned to $\mathrm{C}-\mathrm{H}$ bending in $\mathrm{Si}-\mathrm{CH}_{2}-\mathrm{Si}$ as $\mathrm{PCS}$ of $\mathrm{SiC}$ backbone. Additional peaks appearing at 2900, 2097 and $1006 \mathrm{~cm}^{-1}$ can be associated with $\mathrm{C}-\mathrm{H}$ stretching, $\mathrm{Si}-\mathrm{H}$ stretching and $\mathrm{Si}-\mathrm{O}-\mathrm{Si}$, $\mathrm{Si}-\mathrm{O}-\mathrm{Ti}$ stretching vibrations, respectively. However, the peaks at 1453,1131 and $681 \mathrm{~cm}^{-1}$ distinctly represent C-C stretching (in-ring), C-O stretching and Ti-O-Ti vibrations in cured-PCS/ TIP/DVB matrix. It could not observed at as-received PCS. The peaks from $\mathrm{C}-\mathrm{C}$ stretching (in-ring) and C-O stretching was thought to be from DVB remaining in the matrix after curing. Ti-O-Ti peaks were thought to be from the reaction between $\operatorname{TIP}^{12}$.

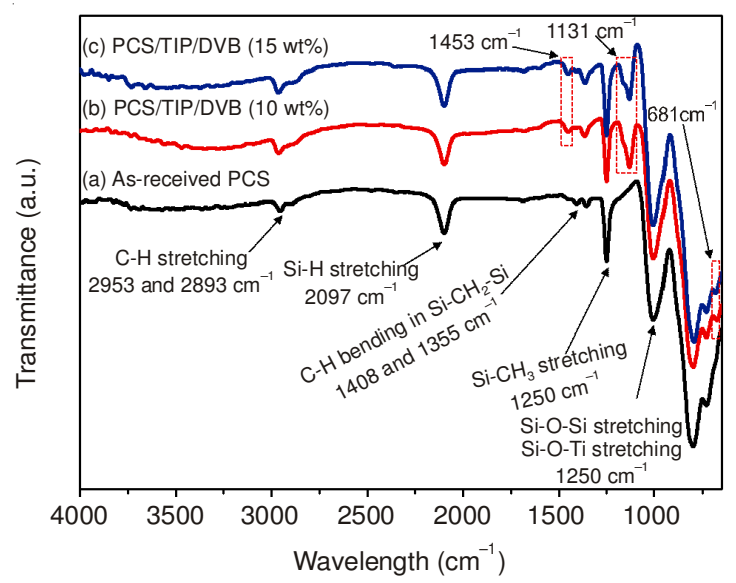

Fig. 3. FT-IR spectra of (a) as-recieved PCS, (b) as cured-DVB $10 \mathrm{wt} \%$ in PCS/TIP and (c) as cured-DVB 15 wt \% in PCS/TIP

Thermal weight losses were assessed to compare the behaviour of the PCS and cured cured PCS/TIP and DVB (10, 15 wt \%), as shown in Fig. 4(a-b). The PCS showed losses at temperatures ranging from $300-700{ }^{\circ} \mathrm{C}$ and exhibited a ceramic yield of $57 \%$ in Fig. 4(a). After curing, the ceramic yield of PCS/TIP and DVB $10 \mathrm{wt} \%$ was $76 \%$. Then, DVB $15 \mathrm{wt} \%$ was a decrease of $74 \%$. This decrease in the ceramic yield was due to the evaporation of all the low-molecular weight PCS and TIP components. And, Fig. 4(b) represents the oxidation of Si-Ti-C-O matrix for carbon contents at only cured matrix. 

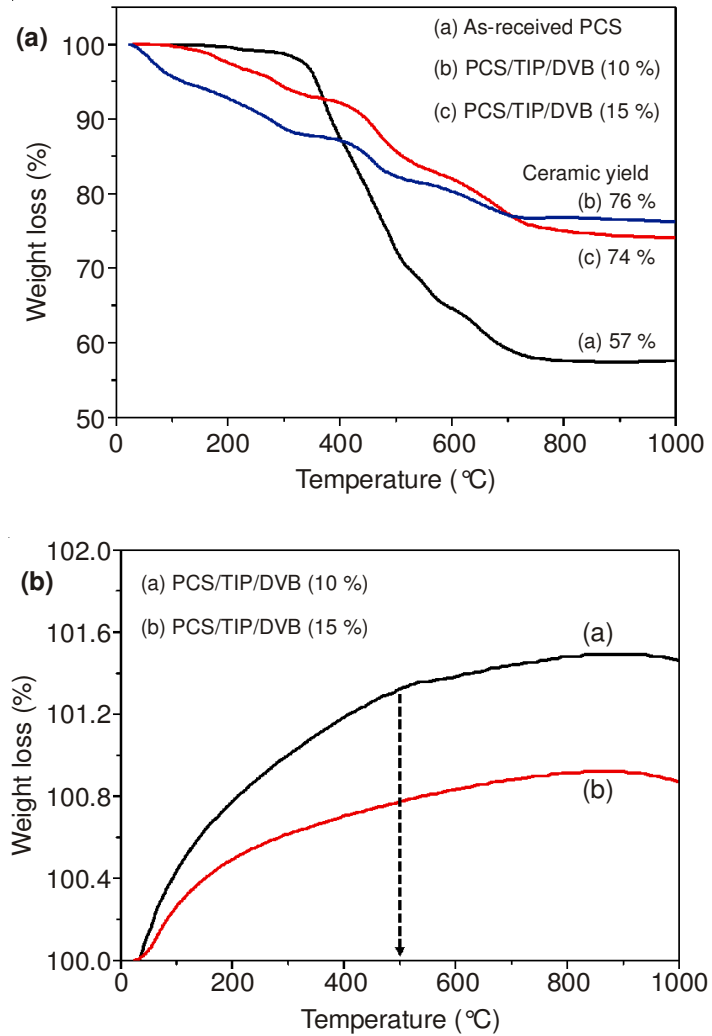

Fig. 4. TGA curves of (a) ceramic yield of PCS and cured matrix in argon atmosphere and (b) ceramic yield of PCS and cured matrix in air atmosphere for carbon contents evaluation

Cured matrix of DVB 10 and 15 wt $\%$ could not shows the different at oxidation to decomposed carbon compounds (CO gas) after $500^{\circ} \mathrm{C}$.

The morphologies and chemical composition analysis by EDS of the Si-Ti-C-O matrix are shown in Fig. 5. Morphologies of Si-Ti-C-O matrix shows as the ceramic matrix. And EDS results such that $51.83,14.78,30.54$ and 2.85 at $\%$ were determined for Si-Ti-C-O matrix. These results are in directly include with the titanium elements in Si-C-O phase matrix. Table-2 showed that the thermal conductivity of TiC is lower than $\mathrm{SiC}$. So the thermal conductivity of Si-Ti-C-O matrix is expected to be lower than $\mathrm{SiC}$. At the high temperature, the temperature gradient of Si-Ti-C-O will be larger than $\mathrm{SiC}$. From this, the stress would be more generated in $\mathrm{Si}-\mathrm{Ti}-\mathrm{C}-\mathrm{O}$ matrix. And also the thermal expansion of $\mathrm{TiC}$ is larger than $\mathrm{SiC}$. This thermal expansion difference could generate the compressive stress region and the tensile stress region. The stress generated by the difference of thermal conductivity and thermal expansion would increase the mechanical strength of Si-Ti-C-O matrix. However, much more research such as properties and fabricated composites is needed in the future as the ceramic matrix.

\begin{tabular}{lcc}
\multicolumn{3}{c}{ TABLE-2 } \\
\multicolumn{1}{c}{ COMPARISON OF SiC AND TiC PROPERTIES ${ }^{13}$} \\
\hline \multicolumn{1}{c}{ Properties } & SiC & TiC \\
\hline Melting point $\left({ }^{\circ} \mathrm{C}\right)$ & 2545 & 3160 \\
Density $\left(\mathrm{g} / \mathrm{cm}^{3}\right)$ & 3.22 & 4.93 \\
Young's modulus $(\mathrm{GPa})$ & 475 & 493.43 \\
Thermal expansion coefficient $(\mathrm{ppm} / \mathrm{K})$ & 3.8 & 7.4 \\
Thermal conductivity $(\mathrm{W} / \mathrm{m} \mathrm{K})$ & 360 & 30.93 \\
\hline
\end{tabular}

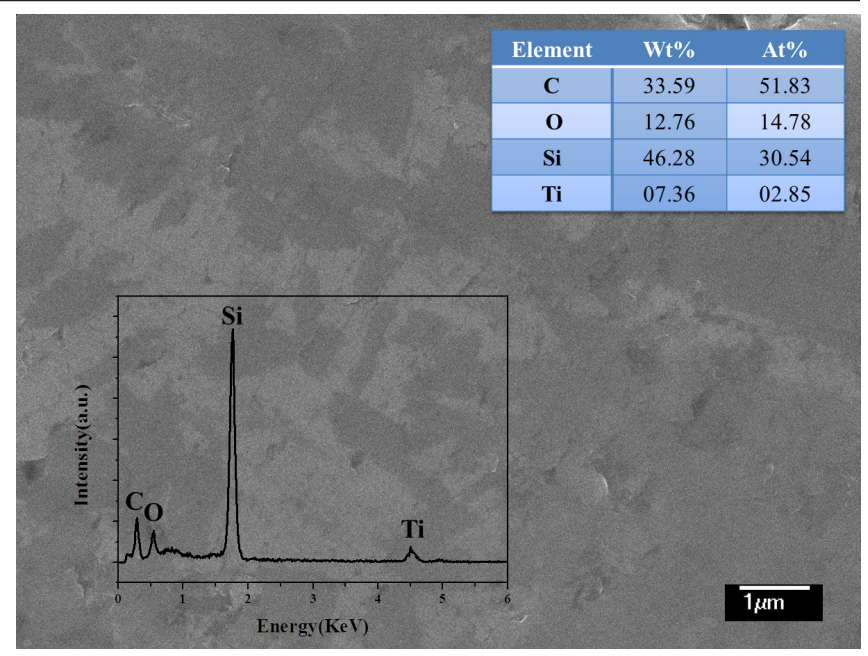

Fig. 5. FE-SEM image and EDS analysis of Si-Ti-C-O matrix for DVB 10 wt $\%$ in PCS/TIP

\section{Conclusion}

Si-Ti-C-O matrix was fabricated by a simple blending using a precursor (PCS) and titanium isopropoxide obtained hardener using divinylbenzene. Characterization of the material as ceramic matrix was shown by the XRD patterns, FT-IR, thermal behaviour, chemical composition and morphologies. Moreover, polytitanocarbosilane (PTCS) does not required which make the Si-Ti-C-O matrix. Therefore, Si-Ti-C-O matrix could be used at fiber/matrix as ceramic matrix for environments.

\section{ACKNOWLEDGEMENTS}

The authors appreciated for the financial supports from Korean Ministry of Knowledge and Economy, under the program of Industrial Convergence Resources Research Program and World Premier Material Research Program and the Fundamental R\&D Program for Core Technology of Materials.

\section{REFERENCES}

1. K. Jian, Z.H. Chen, Q.S. Ma and W.W. Zheng, Mater. Sci. Eng. A, 390, 154 (2005).

2. K. Itatani, T. Tanaka and I.J. Davies, J. Eur. Ceram. Soc., 26, 703 (2006).

3. H.A. Liu and K.J. Balkus Jr., Mater. Lett., 63, 2361 (2009).

4. Y. Xu, L. Zhang, L. Cheng and D. Yan, Carbon, 36, 1051 (1998).

5. J.C. Bae, K.Y. Cho, D.H. Yoon, S.S. Baek, J.K. Park, J.I. Kim, D.W. Im and D.H. Riu, Ceram. Int., 39, 5623 (2013).

6. A.R. Bunsell and A. Piant, J. Mater. Sci., 41, 823 (2006).

7. P.H. Kang, J.P. Jeun, D.K. Seo and Y.C. Nho, Radiat. Phys. Chem., 78, 493 (2009).

8. K. Jian, Z.H. Chen, Q.S. Ma and W.W. Zheng, Mater. Sci. Eng. A, 390, 154 (2005)

9. Z. Li, H. Li, S. Zhang and K. Li, Ceram. Int., 38, 3419 (2012).

10. T. Ogasawara, T. Ishikawa, H. Ito, N. Watanabe and I.J. Davies, J. Am. Ceram. Soc., 84, 1565 (2001).

11. G.A. Pribytkov, Y.V. Svitich, I.V. Polev, M.I. Vagner and S.S. Borisov, Refr. Ind. Ceram., 39, 179 (1998).

12. V.A. Zeitler and C.A. Brown, J. Phys. Chem., 61, 1174 (1957).

13. J.F. Shackelford and W. Alexander, CRC Materials Science and Engineering Handbook, Lewis Publishers, pp. 50, 279, 508 (2000). 